\title{
CORPO, FESTA E PERFORMATIVIDADE: ENCRUZILHADAS E REFLEXÕES DESDE A ORALIDADE POPULAR BRASILEIRA
}

\author{
Body, Festivity and Performativity: \\ crossroads and thinkings since the Brazilian popular orality
}

\author{
Sayonara Pereira \\ Daniel Santos Costa \\ Universidade de São Paulo - USP
}

Resumo: Neste texto, buscamos refletir sobre o corpo no contexto da oralidade popular brasileira, munidos de um referencial pós-colonial. Diante de nossa análise, evidenciamos a revisão de uma postura metodológica e epistemológica de investigações que lançam olhares ao universo performativo periférico e marginal, lócus em que está inserida a maior parte das manifestações performativas da oralidade popular brasileira, onde O corpo é uma festa!

Palavras-Chave: Corpo, Dança, Festa, Oralidade, Performatividade.

Abstract: In this paper we reflect on the body in the context of Brazilian popular orality provided with a post-colonial framework. In front of our review we noted the review of a methodological and epistemological stance of research focus looks to peripheral performative universe and marginal, locus in which they operate most performing expressions of Brazilian popular orality, where The body is a festivity!

Keywords: Body, Dance, Festivity, Orality, Performativity. 
A Igreja diz: O corpo é uma culpa. A ciência diz: $O$ corpo é uma máquina.

A publicidade diz: O corpo é um negócio.

O corpo diz: Eu sou uma festa.

\section{Eduardo Galeano $^{1}$}

Parafraseamos 0 poeta uruguaio Eduardo Galeano na escrita deste artigo, no qual "O corpo é um festa!". Desse modo, concordamos a perspectiva apontada sobre o corpo e seguimos um caminho, intersecionando uma possibilidade de pensamento desde a oralidade popular brasileira. Mas, se falamos em corpo, por que não utilizar corporeidade popular brasileira em detrimento de oralidade popular brasileira?

Elucidamos, no contexto de nossas pesquisas, a oralidade relacionada nos efeitos da presença, do ambiente e do corpo em ação numa concepção singular de performance, segundo preceitos de Paul Zumthor (1997) e de Leda Maria Martins, que apresenta o termo oralitura, definindo-o da seguinte maneira.

O termo oralitura, da forma como o apresento, não nos remete univocamente ao repertório de formas e procedimentos culturais da tradição linguística, mas especificamente ao que em sua performance indica a presença de um traço cultural estilístico, mnemônico, significante e constitutivo, inscrito na grafia do

1 GALEANO, Eduardo. As Palavras Andantes. Trad. Eric Nepomuceno. São Paulo, L\&PM, 1994. corpo em movimento e na velocidade. (MARTINS, 2001, p. 84)

Tais definições estão em acordo com a ideia de escrituras, inscrições e experiências não registradas, como é o caso de grande parte da cultura tradicional brasileira (ou o que comumente é chamado de cultura popular brasileira) e aproxima-se, de certo modo, aos processos formativos nas artes da cena aliados à poética da oralidade, daquilo que é voz, movimento, ação, ou seja, experiências orais. Neste lugar, pleiteamos uma similaridade entre oralidade e corporeidade, pois, no contexto em que interseccionamos tal reflexão, a oralidade envolve também o corpo, ou seja, a oralidade, assim como define Setenta (2008, p. 143), pode ser considerada uma "fala construída no corpo e pelo corpo".

Recorremos, portanto, ao termo oralidade popular brasileira para nos referir a tradições populares ou tradições orais onde, por exemplo, a noção de tempo, espaço e verdade histórica são problemas centrais para que possamos entendê-las. Em tais espaços, o passado está vivo e uma parte do presente e do futuro existe hoje desde sempre. São espaços do acontecimento, conceito que vem colocando em crise a ideia de história (ZOURABICHVILI, 2016; DOSSE, 2013). Aqui também, a ideia de oralidade está imbricada à ideia de corpo, onde "a oralidade não se reduz a ação da voz, mas expansão do corpo, embora não o esgote. A oralidade implica 
em tudo o que, em nós, se endereça ao outro: seja um gesto mudo, um olhar" (ZUMTHOR, 1997, p. 203).

Assim, ao lidar com investigações e metodologias nesses campos de estudo, é preciso despir-se de noções de métodos e técnicas da ciência moderna. É preciso "abrir mão do mito da fonte escrita para se confrontar com problemas metodológicos" (CALVET, 2011, p. 117). É preciso confrontar-se com a oralidade, fugir das simplificações, apreender fazendo, brincando, dançando, cantando, imaginando.

Os processos da oralidade acontecem, muitas vezes, de modo análogo ao o pensamento da cena, aproximando o Teatro e a Dança, da Antropologia e Sociologia. Os Estudos da Performance já possuem inúmeras produções alicerçadas nas Performances Culturais, termo que é usado para referir-se a esse universo da oralidade, onde memória é conhecimento. Nesse lugar, é importante ressaltar o amparo e busca de diálogo constante com autores como Daiana Taylor (2013), Leda Martins (2003, 2001 e 1997), Ligiéro (2011), Richard Schechner (2012, 2011 e 2006) e Victor Turner (2013). Especialmente, voltamos à Leda Martins, pesquisadora brasileira que veio tramando, até então, a ideia de "oralitura". A autora nos diz que "numa performance da oralidade, por exemplo, o gesto não é apenas uma representação mimética e instaura a própria performance, ou ainda, o gesto não é simplesmente narrativo ou descritivo mas performativo." (MARTINS, 2003, p. 65). Igualmente, no universo da oralidade, o corpo é um sistema complexo, lugar de saber, no qual os sujeitos que daí são insurgidos são tecidos de memória, onde o corpo significa e é significado. Tais articulações serão possíveis com o pensamento de Paul Zumthor (2007, 1997), acerca da oralidade e performance, pois o autor também estabelece relação ente corpo, oralidade e performatividade.

Ao falar em corpo nesta paisagem da oralidade, é possível logo flexionar, corporalidade (corpo + oralidade), como uma qualidade movente do corpo performativo. Desta articulação é possível perceber um abrangente conceito que possa mover o corpo em processos de criação, investigação e performance. Para Zumthor (2007), na poesia da oralidade, a voz assume condição de escritura, onde corpo e memória integram-se na expressão de um pensamento expandido e não linear num evento (acontecimento) atualizado no presente da ação performativa, onde corpo é som, é silêncio, é $f(r)$ esta.

Dessa $f(r)$ esta, encruzilhamos olhares para um campo vasto: elementos estruturais - danças, sonoridades, corporeidades, rituais, o pensamento mítico (imaginação, símbolos e metáforas) articulando com a criação performática. $O$ pensamento sobre 0 corpo nesta complexidade associase, em metáfora, à festa. De alguma maneira, a festa é uma forma de 
produção de conhecimento, uma forma de apropriação diferenciada do mundo, paisagens da multidimensão, do acontecimento, da contemplação, do estado de presença, dos contágios, contatos e, certamente, de conflitos.

Ao adentrar esse espaço de pensamento, e diante da tentativa de compressão dos fenômenos no universo da oralidade popular brasileira, tem sido necessário despir os olhares colonizados que imperam nossas reflexões. Assumindo tal postura, nos engajamos na compreensão sobre os registros e experiências advindas do projeto de doutorado $D a$ Oralidade Popular Brasileira a uma Dança Teatral Performativa: o corpo pós-colonial como um lugar de experiência, onde o sujeito-pesquisador oriundo do universo das Folias de Reis, em Minas Gerais e Goiás, espectador das performancesrituais de Umbanda, especialmente na cidade de Campinas - São Paulo, além do pertencimento ao Movimento dos Sem-Terra, em Minas Gerais, durante a década de 1990 e meados dos anos 2000 , esboçamos estratégias plausíveis para adentrar tais espaços. A crítica póscolonial é trazida como contexto para tal articulação, principalmente junto ao pensamento de Boaventura de Sousa Santos acerca das Epistemologias do Sul, que:

Trata-se do conjunto de intervenções epistemológicas que denunciam a supressão de saberes levada a cabo, ao longo do último século, pela norma epistemológica dominante, valorizam os saberes que resistiram com êxito e as reflexões que estes tem produzido e investigam as condições de um diálogo horizontal entre conhecimentos. A esse diálogo entre saberes chamamos ecologia dos saberes". (SANTOS e MENESES, 2010, p. 11)

Ao lado de Santos e Meneses, num entrelaçamento também de teorias contemporâneas para disparar o cerne desta discussão, trazemos para esta conversa autores diversos, pois, ao adentrar o terreno da oralidade popular brasileira, percebemos que este espaço aproxima-se da noção de interdisciplinaridade ou trasdisciplinaridade, pois oferece-nos possibilidade de um mover epistêmico que insurge de tais processos, nos quais confrontam e dialogam. É lugar contato/contágio/conflito, no qual, nem sempre acontece amigavelmente, pois encruzilham concepções e ideais diferenciados, como reflexo da complexidade da vida. Como exemplo de tais processos, apresentamos um trecho que exprime tal dinamismo:

Essa percepção cósmica e
filosófica entrelaça, no mesmo
circuito de significância, o tempo, a
ancestralidade e a morte. A primazia
do movimento ancestral, fonte de
inspiração, matiza as curvas de uma
temporalidade espiralada, na qual
os eventos, desvestidos de uma
cronologia linear, estão em processo
de uma perene transformação.
Nascimento, maturação e morte
tornam-se, pois, eventos naturais,
necessários na dinâmica mutacional e
regenerativa de todos os ciclos vitais


e existenciais. Nas espirais do tempo, tudo vai e tudo volta. (MARTINS, 2001. p. 84)

Perceber e olhar esse viés cultura popular brasileira implica, contudo, um olhar para o sincretismo e a liminaridade que se dão em encruzilhadas Os espaços de encruzilhadas como potencial lócus de encontros e desencontros podem ser relacionados a um espalho simbólico, no qual se processam caminhos operadores de linguagens e discursos, ou seja, trata-se de um entrelugar, como nomeou o pensador indiano Homi Bhabha (2013). O autor definiu esta ideia como espaço propiciador de uma produção de significados diversos e, portanto, de sentidos, de elaboração discursiva, determinadas pelos próprios discursos que ali coexistem. Nesse lugar, noções de um corpo-sincrético ou corpo-encruzilhada podem ser pensadas como indicativos dos efeitos de processos e cruzamentos discursivos diversos, intertextuais e interculturais. Martins (1997) aborda a encruzilhada como lugar radial de centramentos, descentramentos, intersecções, cruzamentos, influências, divergências, cisões, fusões, rupturas, multiplicidade e convergência, unidade e pluralidade, origem e disseminação.

Para Bhabha (2013), tal espaço não está dentro nem fora, mas numa relação tangencial entre essa fronteira ou uma zona de negociação entre dentro-fora, centro-periferia ou, ainda, global-local para a desestabilização de categorias centralizadoras do pensamento utópico, num posicionamento tensivo, complexo e híbrido.

Sendo a encruzilhada a constituinte dos processos de encontros, conflitos, sincretismos, aproximamos tal espaço como uma festa, o espaço da ação e do acontecimento no contexto da oralidade popular brasileira. $\mathrm{O}$ acontecimento da festa permite perceber a performatividade dos corpos nesses espaços liminares, pois, nos Estudos da Performance, tal conceito é entendido como o próprio acontecimento, ou seja, o aqui e agora das ações, no instante e na experiência, com toda sua expressividade e singularidades, lócus exponencial para desestabilização do pensamento.

A festividade como forma primordial acentuada da civilização humana é definida por Bakhtin (1999) como sendo um espaço de expressão, imbricando tradição, símbolos e práticas. A festa poderá ser pensada como uma maneira de transmitir para novas gerações práticas tradicionais e históricas a determinados processos de vida e trabalho. Nesses espaços, percebemos o universo da oralidade popular brasileira constituído não só de símbolos e gestualidade, mas de uma apropriação corporal singular dos sujeitos que habitam tais espaços, recriando através de seus arquivos corporais, contando-nos, no espaço do aqui e agora da performance, uma história incorporada numa integração entre passado-presente-futuro, como 
nos é apontado abaixo:

A festa popular é o grande e fecundo
momento a nos ensinar que a arte de
viver e de compreender a vida que nos
envolve está na perfeita integração
entre o velho e o novo. Sem o novo,
paramos no tempo. Mas sem o velho
nos apresentamos ao presente e ao
futuro de mãos vazias. (PESSOA,
2009, p. 44)

A festa como perspectiva do pensamento e estratégia de ação pode se relacionar a um espaçotemporal distanciado dos aspectos positivistas que estancam conceitos e posturas metodológicas. Ela instala-se, portanto, num momento de rupturas em relação a um universo obediente e vinculado a uma necessidade já imposta de sobrevivência. Para Ribeiro Junior (1982), a festa é como uma escola do povo e "uma compreensão adequada pode iluminar procedimentos, em que a dimensão lúdica e a pedagógico-política da festa popular se interfecundam sem cair na manipulação do esvaziamento" (1982, p. 11).

A festa opõe-se ao cotidiano, contudo vincula-se a ele, transfigurando esse espaço numa espetacularização que, ao romper a lógica cotidiana, abre caminho para a própria arte. A festa ganha status de performance e sua festividade a dimensão da performatividade. Em conformidade com esse status, a festa, então, adere-se à dimensão da cultura, expressando modos de fazer, pensar, estar e existir no mundo. Com esse descrever, a festa pode ser definida como terreno do possível.

O espaço da festa é múltiplo e composto, nele, as metáforas provindas do imaginário são potências para pensar as suas estruturas e alargar uma visão setorizada. Urge romper com uma visão mesquinha e reducionista desse acontecimento. Nesse terreno complexo, há a evidente necessidade do entendimento da festa para além da festa "fato", para a festa "acontecimento", na qual estão implicadas questões da dialética sociocultural, desde as carências até as disputas de poder.
A festa é formada por experiências históricas; é fruto das movimentações e interconexões dos corpos-culturais que constituem uma das formas mais reveladoras do modo de ser de um grupo, de uma cidade e de um país, é nesse espaço 'intervalar', que ficam suspensas algumas normas sociais e outras são invertidas". (CASTRO JÚNIOR, 2014, p. 26-27)

Perceber o acontecimento da festa como este espaço intervalar, ou encruzilhada, abre frestas para pensarmos o corpo como lugar de experiência que, de acordo com Larrosa (2014), trata-se de um modo de habitar o mundo além, onde a experiência não pode ser conceituada. Ela é a própria vida, transbordamento, criação, invenção, acontecimento e, neste contexto, pronunciam-se crenças e modos de pensar das comunidades marginais, indicando a confluência de diversos sistemas epistêmicos. O corpo, que é festa, festeja, narra saberes, torna-se visível na instabilidade entre 
sagrado e profano, entre luzes e trevas, entre certo e errado e tantas outras dicotomias. Trata-se de um corpo que é fé e divertimento, é vida e é arte, embevece-se de tragédias e comicidades, ou seja, um corpo em exuberante produção de vida.

$\mathrm{Na}$ oralidade popular brasileira, no cotidiano e nos espaços de festividades, é possível vislumbrar uma dramaturgia corporal através dos estados do corpo, mas sempre surpreendidos pelo fazer vivo desses acontecimentos performativos, encontrando lugar no tempo e espaço através da experiência. Nestes espaços, corpo não é apenas uma imagem cultuada, mas é o próprio acontecimento da experiência, buscando sempre estratégias adaptativas, pois, segundo Diana Taylor (2013), "os saberes corporificados são aqueles que foram constituídos historicamente na relação com a experiência social e que compõem nosso repertório, podendo ser imediatamente utilizados na solução de novos problemas".

Taylor (2013) nos diz que as crenças e os modos de pensar das comunidades marginais indicam a confluência de diversos sistemas epistêmicos, aproximando-se ao conceito do "pensamento mítico", do antropólogo mexicano Alfredo López Austin. Este conceito permite aproximação com a ideia do Pensamento Selvagem, de Lévi-Strauss (1997), que se aproxima a um bricoleur, aquele que reorganiza o mundo em combinações, sem uma lógica utópica, pois o mito vivido como uma experiência não evoca necessariamente o sentido ou a verdade que tanto postula o saber científico, mas habita a experiência sensível, como uma maneira de pensar não linear, acessa os recursos mnemônicos e, de acordo com Taylor (2013, p. 138) ironicamente, se parece com o conceito digital de redes, circuitos e interconectividade.

Com tais apontamentos, nos permitimos afirmar que, no momento do acontecimento da festa, há o pronunciamento de conhecimento incorporado. Desse modo, a festividade detona uma rede onde guardamos tudo que vivemos, mas é preciso atentar que:

$$
\begin{aligned}
& \text { (...) o conhecimento é como o } \\
& \text { coração, escondido, batendo, } \\
& \text { brilhando imperceptivelmente, } \\
& \text { regulando canais que correm para } \\
& \text { trás e para frente para outros canais, } \\
& \text { torrentes e correntes inesperadas, } \\
& \text { controladas pela complexidade } \\
& \text { radial de ventrículos centrais muito } \\
& \text { poderosos. (TAYLOR, 2013, p. 126) }
\end{aligned}
$$

Nesse momento, os apontamentos supracitados deflagram a metáfora de um espaçotemporal da oralidade popular brasileira como festa, na qual está nitidamente ancorada na presença e multidimensão. Tais fatores corroboram comas proposições de performatividade, ou seja, onde o discurso é o exercício do corpo em ação, onde o acontecimento é experiência ou a experiência como acontecimento. Daqui, é possível reelaborar suposições metodológicas e mesmo epistemológicas que partam 
de uma postura da encruzilhada, metáfora da festa, ativado pelo desejo, pela alegria, pela intuição, pelo instinto. Desse mesmo lugar, é necessário reavivar uma postura metafórica, pois como elucida Domenici (2009) tal proposição torna-se pista para estudar o próprio corpo no contexto da oralidade popular brasileira.

Apresentamos, diante disso, como proposta de investigação, a ideia de um corpo pós-colonial como um lugar de experiência, um corpo sincrético, o qual simboliza um local para se colocarem questões epistemológicas sobre as artes da cena, tendo em vista a perspectiva do corpo como operador de pensamento, buscando uma episteme plausível, "considerando epistemologias locais, que incluem visões de mundo e formas de conhecimentos bastante específicas" (2009, p. 9) e também como Costa e Navarro elucidam abaixo:

\begin{abstract}
Como modelo de vida menos dicotômico, observa-se, por exemplo, que não há momentos específicos de treinamento, pautados na oralidade não restrita à fala - e na corporeidade, os processos de transmissão e de transformação vão ocorrendo sem grandes dores. (2014, p. 149)
\end{abstract}

Os olhares que tecemos com as Folias de Reis e as Umbandas, manifestações da cultura brasileira, demonstram aptidão destas a um sincretismo dinâmico para sua manutenção na contemporaneidade. Precisamos, contudo, estar atentos ao conhecimento local e nos adequarmos acerca da dimensão extensa e complexa desses terreiros e territórios, especialmente a popular, tem-nos a ofertar sem os fantasmas das essências românticas e colonizadoras, pois o colonizado, como observa Santos (2010a), sempre sofre com um déficit de representação em nome próprio. Entendemos, então, este momento como terreno propício a pulsão de uma transgressão metodológica (SANTOS, 2010b, p.78), num momento intitulado pelo autor de paradigma emergente, no qual "a distinção hierárquica entre 0 conhecimento científico e o conhecimento vulgar tenderá a desaparecer e a prática será o fazer e o dizer da filosofia da prática" (2010b, p. 20).

As Folias de Reis são manifestações performativas vinculadas ao catolicismo popular e que se baseiam na atualização do mito de nascimento do Menino Jesus. Os manifestantes buscam não somente rememorar suas narrativas fundantes, mas atualizam-nas performativamente por meio de toda diversidade de símbolos, ritos, gestos, cantos, músicas, ritmos, cores e do sentido mítico de cada um desses elementos. Volta-se ao mito, numa encruzilhada espaçotemporal intangível. Trata-se, contudo, de uma manifestação que acontece no espaço da cidade, de forma processional, conhecida como giros que se movimentam, geralmente entre dezembro e janeiro, cumprindo um roteiro de saída, visitações e chegada, considerada uma das manifestações mais amplas em rituais, sendo a 
festa o acontecimento principal. Tal acontecimento marca o fim e novamente o começo, pois nas manifestações da oralidade popular brasileira há um intrínseco movimento espiralar untado à conexão passado-presente-futuro.

Uma das figuras mais emblemáticas de tal manifestação é o palhaço ou bastião. Diferentemente dos corpos densos, frágeis, lentos dos foliões mais velhos, os palhaços das Folias apresentam um corpo leve, ágil, mesmo quando também são pessoas idosas. Há uma dualidade muito bem apresentada, onde sagrado e o profano manifestam-se em seus corpos performativos e tais palhaços dançam, pulam, rolam no chão. São criadores excêntricos, no sentido strictu da palavra, mascarados e com vestimenta e adereços bem marcantes. São personagens enigmáticas, provocadores de controvérsias, sendo singular figura/personagem que apresentam movimentos dançantes, ágeis e de descolamentos coreográficos e declamações de chulas (versos burlescos e jocosos) que destoam da procissão que os sucedem no espaço ritual, onde se vincula cada vez mais a ideia cristã da manifestação, fato menos observado quando tais manifestações ainda eram de primazia rural. Contudo, nos aliamos ao sentido da performatividade que tais manifestações podem provocar, seja numa postura metafórica, no sentido mítico ou no fazer analógico. A capacidade de tornar-se outro e o mistério do jogo manifestamse de modo marcante no costume da mascarada, que, conforme Huizinga (2007, p. 16), atinge o máximo da natureza "extra-ordinária" do jogo.

O olhar que tecemos com as Umbandas está muito mais na mitopoética da sua manifestação do que na estrutura ritual em si. Tal manifestação “(...) é um exemplar desse registro sincrético, fundindo em seu tecido cognitivo e ritual, elementos de outros sistemas religiosos nagô, banto, católico, tupi-guarani, kardecista, espírita numa reformulação sui generis" (Martins, 1997, p. 14).

Como uma religião que vem se desenvolvendo, desde a década de 1930, num contexto de intensos sincretismos entre tradições religiosas, a aglutinação umbandista é uma composiçãosistêmica, evemao encontro de uma perspectiva da formação da sociedade brasileira, mestiça, híbrida, limiar, ou seja, uma encruzilhada onde poderemos profanar estratégias para olhar, metodologias para amalgamar processos e uma episteme plausível para o contexto que habitamos.

Da ideia de um pensamento marginal, provocamos que a partir da experiência é possível alcançar caminhos singulares para a solidificação de uma produção artística contemporânea, pois a experiência está relacionada à influência que o indivíduo recebe do meio. No entrelugar, conforme definiu Bhabha (2013), ou a encruzilhada, de Martins (1997), um espaço de intersecções disponível ao híbrido será sempre possível a profusão do novo, do 
combate as ideias paradigmáticas dos dualismos, pois vê uma combinação entre os duplos, como homem e ambiente, natureza e sociedade, arte e ciência.

Ao olhar para a oralidade popular brasileira, operaremos na lógica do mito, uma relação espaçotemporal ancorada no acontecimento, fato que "foi escorraçado na medida em que foi identificado com a singularidade, a contingência, o acidente, a irredutibilidade, o vivido" (MORIN, 2005, p. 181). Deslocando o olhar para tais espaços da oralidade, necessitaremos romper muito mais a lógica que predomina em muitos processos artísticos contemporâneos: a imitação colonial, conceito postulado por Santos (2008).

Aliado a este estudioso português, nossa investigação está enraizada numa perspectiva pós-colonial, em prática performativa e os discursos que constroem as narrativas coloniais, aproximando da escrita do próprio colonizado que traz imbuído em sua ação (discurso performativo) um modo de organizar o pensamento artístico as ausências que o discurso hegemônico ocidental nacionalizante e normativo postulou, apontando para tais prerrogativas: a experiência como acontecimento, a ambiguidade de referências, proposições e intervenções práticas, multiplicidade de perspectiva, criação de novos argumentos, novos posicionamentos diante do mundo, novos sentidos e mais uma vez reivindicar a experiência, o acontecimento da experiência.

(...) o corpo em performance é, não apenas, expressão ou representação de uma ação, que nos remete simbolicamente a um sentido, mas principalmente local de inscrição de conhecimento, conhecimento este que se grafa no gesto, no movimento, na coreografia, nos solfejos da vocalidade, assim como nos adereços que performaticamente o recobrem. Nesse sentido, o que o corpo se repete não se repete apenas como hábito, mas como técnica e procedimento de inscrição, recriação, transmissão e revisão da memória do conhecimento, seja este estético, filosófico, metafísico, científico ou tecnológico, etc. (MARTINS, 2003, p. 66)

Essa reivindicação chega aqui na forma de uma obra artística eagarrada no corpo. Ô de Casa? Ô de Fora! ou a história do homem que pediu uma Folia a Pombagira Cigana (https://www.youtube.com/ watch?v=8LBh3OG00j8), estreado em 2014, trama uma possiblidade de ser brasileiro e uma organização singular da (i)materialidade do processo. Fruto da hibridização de linguagens, das experiências em processo, do corpo em constante estado de criação, e atravessado transversalmente por uma marginalidade cênica, nos preocupamos com o diálogo do sujeito com o mundo. Tal percurso culminou no que denominamos uma Dança-Teatro Brasileira (COSTA, 2016), enredada na própria dramaturgia das manifestações da oralidade experienciadas. 
Ao assumir o risco propositivo da exclamação $O$ corpo é uma festa! apostamos para além do diálogo com a oralidade popular brasileira, mas uma tentativa de aqui se instalar. Fugindo do olhargeneralizador, noespaçointersticial da encruzilhada, estabelecemos nosso posicionamento político como prática performativa, um espaço do aqui e agora, da não representação e do não mimetismo. Nesta perspectiva, o processo de criação é produção de conhecimento pautada em inquietações das negociações binárias tais como singular/coletivo, eu/outro, teoria/ prática, presença/representação, onde o corpo fala, diz, performa seu ponto de vista sobre o mundo.

Recebido em: 30/11/2016

Aceito: 10/02/2017

\section{Referências Bibliográficas:}

BAKHTIN, Mikhail. M. A cultura popular na Idade Média e no Renascimento: o contexto de François Rabelais. São Paulo: Hucitec, 1999.

BHABHA, Homi. K. O local da cultura. Trad. Myrian Ávila, Eliana Lourenço de Lima Reis, Gláucia Renate Gonçalves. Belo Horizonte: Ed. UFMG, 2013.

CALVET, Louis-Jean. Tradição Oral \& Tradição Escrita. Trad. Waldemar Ferreira Netto, Maressa de Freitas
Vieira. São Paulo: Parábola Editorial, 2011.

CASTRO JUNIOR, Luís Victor. Festa e corpo: as expressões artísticas nas festas populares baianas. Salvador: EDUFBA, 2014.

COSTA, DanielS. Cena e Conhecimento: esboçando corpos emblemas. In: COSTA, Daniel S. (Org.) Estudos sobre o corpo. Jundiaí: Paco Editorial, 2017.

COSTA, Daniel S. (Org.) Estudos sobre o corpo. Jundiaí: Paco Editorial, 2017.

COSTA, Daniel S.; PEREIRA, Sayonara. Da oralidade popular brasileira a uma dança teatral performativa: o corpo pós-colonial como lugar de experiência. Revista Conceição|Conception (Universidade Estadual de Campinas), vol. $05, n^{\circ} 01$, p. 58-69, 2016. Disponível em: https://goo.gl/vJg5Rp. Acesso em 26 de nov. de 2016.

COSTA, Daniel S. Encruzilhadas de uma dança-teatro brasileira: $f(r)$ icção arte-vida no processo criativo. Curitiba: Prismas, 2016.

COSTA, Daniel S.; NAVARRO, Grácia. Encruzilhadas do processo criativo: do mito à poética da cena. In: SOARES, Marília V.; ANDRAUS, Mariana B. M.; WILDHAGEN, Joana (Orgs.). Mitos e Símbolos na Cena Contemporânea: Interlocuções oriente-ocidente. Jundiaí: Paco Editorial, 2014.

COSTA, Daniel. S. Corpo, Imagem, Experiência: atravessamentos 
mnemônicos. Revista Rascunhos (UFU), v. 03, no 01, p. $53-70,201$ 6. Disponível em: https://goo.gl/cLqpvs. Acesso em: 26 de nov. de 2016.

COSTA, Daniel. S. Sincretizando o conhecimento na encruzilhada entre a cena, o sujeito e oralidade popular brasileira. Revista Arte da Cena, v. 02, $\mathrm{n}^{\circ}$ 01, p. 49-6 8, 2015 . Disponível e $\mathrm{m}$ : https://goo.gl/zKubYS. Acesso em: 26 de nov. de 2016.

COSTA, Daniel S. Encruzilhadas do

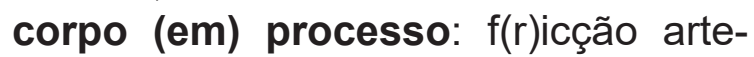
vida na criação de uma dança-teatro brasileira. 2014. Dissertação (Mestrado em Artes da Cena). Instituto de Artes, Universidade Estadual de Campinas, 2014.

COSTA, Daniel S. Histórias e Memórias de Folias de Reis. Ituiutaba, MG: Egil, 2010.

DOMENICl, Eloisa. A pesquisa das danças populares brasileiras: questões epistemológicas para as artes cênicas. In: Cadernos do GIPE-CIT: Grupo Interdisciplinar de Pesquisa e Extensão em Contemporaneidade, Imaginário e Teatralidade. Universidade Federal da Bahia. N ${ }^{\circ}$. 23, out, 2009. Salvador/BA: UFBA/PPGAC, 2009.

DOSSE, François. Renascimento do acontecimento: um desafio para o historiador: entre Esfinge e Fênix. Tradução de Constancia Morel. São Paulo: Editora UNESP, 2013.

FANON, Frantz. Os condenados da terra. Juiz de Fora: Ed. UFJF, 2005.

HALL, Stuart. A identidade cultural na pós-modernidade. Trad. Tomaz Tadeu Silva e Guacira Lopes Louro. Rio de Janeiro, DP\&A, 2011.

HUIZINGA, Johan. Homo ludens: o jogo como elemento da cultura. 5 edição. São Paulo: Perspectiva, 2007.

INGOLD, Tim. Estar Vivo: ensaios sobre movimento, conhecimento e descrição. Tradução de Fábio Creder. Petrópolis, RJ: Vozes, 2015.

LARROSA, Jorge. Tremores: escritos sobre experiência. Belo Horizonte: Autêntica, 2014.

LÉVI-STRAUSS, Claude. Mito e Significado. Lisboa, Edições 70, 2007.

LÉVI-STRAUSS, Claude.

Pensamento Selvagem. Trad. Tânia Pellegrini $-2^{\mathrm{a}}$ Ed. Campinas, SP, Papirus, 1997.

LIGIÉRO, Zeca. Corpo a corpo: estudo das performances brasileiras. Rio de Janeiro: Garamond, 2011.

MARTINS, Leda. Performances da oralitura: corpo, lugar da memória. Letras (Santa Maria), Santa Maria, v, 25, p. 55-71, 2003.

MARTINS, Leda. Oralitura da memória. In FONSECA, M. N. S. (Org). Brasil afro-brasileiro. 2 ed. Belo Horizonte: Autêntica, 2001.

MARTINS, Leda. Afrografias da 
Memória. São Paulo: Perspectiva, 1997.

MORIN, Edgar. Ciência com Consciência. Trad. Maria D. Alexandre e Maria Alice Sampaio Dória. Rio de Janeiro: Bertrand Brasil, 2005.

ORTIZ, Renato. A morte branca do feiticeiro negro: umbanda e sociedade brasileira. São Paulo: Brasiliense, 1999.

PESSOA, Jadir de M. Saberes em Festa: gestos de aprender e ensinar na cultura popular. Goiânia: UCG: Kelps, 2009.

RIBEIRO JUNIOR, Jorge C. N. A festa do povo: pedagogia de resistência. Petrópolis: Vozes, 1982.

SANTOS, Boaventura. S.; MENESES, Maria P. Epistemologias do Sul. São Paulo: Editora Cortez, 2010a.

SANTOS, Boaventura de S. Um discurso sobre a ciência. São Paulo: Editora Cortez, 2010b.

SANTOS, Boaventura de S. A gramática do tempo - para uma nova cultura política. São Paulo: Cortez, 2008.

SCHECHNER, Richard. Performance Studies: An introduction. USA/Canada: Routledge, 2006.

SCHECHNER, Richard. Estudios de la representación. Uma introducion. Richard Schechner. Tad. Rafael Sevogia Albán. México: FCE, 2012.

SCHECHNER, Richard. Pontos de contato entre 0 pensamento antropológico e teatral. Cadernos de Campo, São Paulo, n. 20, p. 1-360, 2011. Disponível em: https://goo.gl/ stFieJ. Acesso em: 11 jan. 2015.

SETENTA, Jussara S. O fazer dizer do corpo: dança e performatividade. Salvador, EDUFBA, 2008.

TAYLOR, Diana. $\mathbf{0}$ arquivo e o repertório: Performance e memória cultural nas Américas. Trad. Eliana Lourenço de Lima Reis. Belo Horizonte: Editora UFMG, 2013.

TURNER, Victor W. O processo ritual: estrutura e antiestrutura. Tradução de Nancy Campi de Castro E Ricardo A. Rosenbusch. $2^{\mathrm{a}}$ ed. Petrópolis, RJ: Vozes, 2013.

ZOURABICHVILI, François. Deleuze: uma filosofia do acontecimento. Tradução de Luiz B. L. Orlandi. São Paulo: Editora 34, 2016.

ZUMTHOR, Paul. Introdução à poesia oral. São Paulo: Hucitec/Educ,1997.

ZUMTHOR, Paul. Performance, recepção, leitura. Trad. Jerusa Pires Ferreira, Suely Fenerich. São Paulo: Cosac Naify, 2007. 
moringa 